\title{
Gas Sensing Performances of ZnO Hierarchical Structures for Detecting Dissolved Gases in Transformer Oil: A Mini Review
}

\author{
He Zhang ${ }^{1 *}$, Wei-Gen Chen ${ }^{1 *}$, Yan-Qiong $\mathrm{Li}^{2}$ and Zi-Hao Song ${ }^{1}$ \\ ${ }^{1}$ State Key Laboratory of Power Transmission Equipment \& System Security and New Technology, School of Electrical \\ Engineering, Chongqing University, Chongqing, China, ${ }^{2}$ School of Electronic and Electrical Engineering, Chongqing \\ University of Arts and Sciences, Chongqing, China
}

OPEN ACCESS

Edited by:

Zhongchang Wang, Laboratório Ibérico Internacional de Nanotecnologia (INL), Portugal

Reviewed by:

Ming-Guo Ma,

Beijing Forestry University, China

Tianming Li,

Leibniz-Institut für Festkörper-und Werkstoffforschung (IFW Dresden),

Germany

*Correspondence:

He Zhang

sophy305410@163.com

Wei-Gen Chen

weigench@cqu.edu.cn

Specialty section

This article was submitted to

Nanoscience,

a section of the journal

Frontiers in Chemistry

Received: 10 August 2018 Accepted: 03 October 2018 Published: 22 October 2018

Citation:

Zhang H, Chen W-G, Li Y-Q and Song Z-H (2018) Gas Sensing Performances of $\mathrm{ZnO}$ Hierarchical Structures for Detecting Dissolved

Gases in Transformer Oil: A Min

Review. Front. Chem. 6:508 doi: 10.3389/fchem.2018.00508
Power transformer is one of the critical and expensive apparatus in high voltage power system. Hence, using highly efficient gas sensors to real-time monitor the fault characteristic gases dissolved in transformer oil is in pressing need to ensure the smooth functionalization of the power system. Till date, as a semiconductor metal oxide, zinc oxide $(\mathrm{ZnO})$ is considered as the promising resistive-type gas sensing material. However, the elevated operating temperature, slow response, poor selectivity and stability limit its extensive applications in the field of dissolved gases monitoring. In this respect, rigorous efforts have been made to offset the above-mentioned shortcomings by multiple strategies. In this review, we first introduce the various $\mathrm{ZnO}$ hierarchical structures which possess high surface areas and less aggregation, as well as their corresponding gas sensing performances. Then, the primary parameters (sensitivity, selectivity and stability) which affect the performances of $\mathrm{ZnO}$ hierarchical structures based gas sensors are discussed in detail. Much more attention is particularly paid to the improvement strategies of enhancing these parameters, mainly including surface modification, additive doping and ultraviolet (UV) light activation. We finally review gas sensing mechanism of ZnO hierarchical structure based gas sensor. Such a detailed study may open up an avenue to fabricate sensor which achieve high sensitivity, good selectivity and long-term stability, making it a promising candidate for transformer oil monitor.

Keywords: ZnO, gas sensors, hierarchical structures, sensitivity, selectivity, stability, gas sensing mechanism

\section{INTRODUCTION}

Power transformer is one of the most critical and expensive devices in high voltage power system (Christina et al., 2018). Generally, oil is used inside the transformer for its operation and can release different fault characteristic gases, such as hydrogen $\left(\mathrm{H}_{2}\right)$, carbon oxides $(\mathrm{CO}$, $\left.\mathrm{CO}_{2}\right)$ and hydrocarbons $\left(\mathrm{CH}_{4}, \mathrm{C}_{2} \mathrm{H}_{2}, \mathrm{C}_{2} \mathrm{H}_{4}\right.$, and $\left.\mathrm{C}_{2} \mathrm{H}_{6}\right)$. Hence, real-time detection of dissolved gases in transformer oil is very essential in order to avoid unexpected failures (Mariprasath and Kirubakaran, 2018). At present, dissolved gas analysis (DGA) remains to be the simplest and most effective diagnostic method for checking latent faults of oil-immersed power transformers (Siada and Hmood, 2015; Fan et al., 2018). Therefore, using highly efficient gas sensors to realtime monitor these dissolved gases in transformer oil is a feasible way to ensure the stability and reliability of power system (Uddin et al., 2016). 
Different types of gas sensors have already been applied in the online detection of dissolved gases in transformer oil, such as resistance-type (Benounis et al., 2008; Sun et al., 2015), optical-type (Ma et al., 2012) and electrochemical-type (Ding et al., 2014). Among diverse types of gas sensors, resistancebased sensors stand out owing to advantages like the small, cheap, high sensitivity and low power consumption (Bodzenta et al., 2002; Yang et al., 2011; Zhao et al., 2017; Xu et al., 2018). With the increasing demand for better gas sensors of higher sensitivity and selectivity (Sun et al., 2012; Gardon and Guilemany, 2013), countless endeavors have been poured on hunting for more suitable sensing nanomaterials. Semiconductor metal oxides (MOS), such as zinc oxide $(\mathrm{ZnO})$, tin oxide $\left(\mathrm{SnO}_{2}\right)$, tungsten oxide $\left(\mathrm{WO}_{3}\right)$, etc., have received wide research for gas sensing applications and so on. Among these, the gas sensing performance of $\mathrm{ZnO}$-based gas sensor was first investigated by Seiyama et al. (1962). As a typical n-type semiconductor material with a direct wide band gap $(\mathrm{Eg} \approx 3.37 \mathrm{ev})$ and large excitation binding energy ( $\sim 60 \mathrm{mev}), \mathrm{ZnO}$ has got important status in various MOS nanomaterials due to its high carrier mobility of conduction electrons, good chemical and thermal stability (Zeng et al., 2015; Das and Sarkar, 2017; Ganesh et al., 2017).

The gas sensing properties of $\mathrm{ZnO}$ greatly depend on its structure and morphology including surface area, size, orientation and crystal density (Cho et al., 2011). Therefore, tailoring the structure and morphology of $\mathrm{ZnO}$ is particularly important to optimize the gas sensing performances (Liao et al., 2008). In particular, the elaborate design of unique three-dimensional (3D) hierarchical architectures can fully achieve this, since such hierarchical structures possess high surface area and fast gas diffusion as well as reduce the agglomerated configuration of low dimensional structures.

$\mathrm{ZnO}$-based gas sensors commonly have the shortcomings of slow response, poor selectivity and lack of long-term stability, which limits the wide applications. To acquire an efficient and reliable dissolved gases sensor, high sensitivity, selectivity, longterm stability, low response / recovery time, low fabrication cost are urgently needed (Wang et al., 2012). This review focuses on the factors that affect the performances (sensitivity, selectivity and stability), the methods to improve these sensor parameters and gas sensing mechanism of $\mathrm{ZnO}$-based gas sensors.

\section{GAS SENSING PERFORMANCES OF ZnO-BASED GAS SENSOR}

\section{Effects of Morphologies About ZnO Hierarchical Structures on Gas Sensing Performances}

Three-dimensional (3D) hierarchical structures are generally recognized as the best candidate for gas sensing performances, compared with low-dimensional structures (Mo et al., 2008; Guo, 2016). They are defined as those assembled by zerodimensional (0D), one-dimensional (1D) and two-dimensional (2D) components, which can be further classified into the following sub-sections. (1) Assembly of 0D structures: Li W. Q. et al. (2015) reported the synthesis of pure $\mathrm{ZnO}$ hollow nanofibers by electrospinning method. The walls of $\mathrm{ZnO}$ nanofibers consist of the aggregation of many individual nanoparticles, as shown in Figure 1A. The sensor based on $\mathrm{ZnO}$ hollow nanofibers exhibits excellent sensing performance for acetone detection, which can be attributed to the large aperture and small diameters provide higher specific surface area for gas adsorption. Chen $\mathrm{H}$. et al. (2016) synthesized the uniformly monodispersed $\mathrm{ZnO}$ nanospheres via a simply hydrothermal route. In particular, all the microparticles on the surface are sphere-shapes and have a rough surface, as shown in Figure 1B. This unique porous structure exhibits perfect sensing performance toward ethanol. (2) Assembly of 1D structures: Lin et al. (2015) reported the hierarchical $\mathrm{ZnO}$ microstructures by hydrothermal method. The morphology of the sample likes a bunch of flowers which is made of uniform nanorods, as shown in Figure 1C. The sensor based on the sample shows a good response. Chen $\mathrm{H}$. et al. (2016) reported the sea-urchin-like $\mathrm{ZnO}$ nanostructures by hydrothermal method. The sample is composed of many strips and radiates from the center, as shown in Figure 1D. The sensor based on the $\mathrm{ZnO}$ sample toward ethanol exhibits high sensitivity and quick response. (3) Assembly of 2D structures: Gu et al. (2011) reported the porous flower-like $\mathrm{ZnO}$ nanostructures by economical hydrothermal synthesis combined with subsequent calcination. Calcination of the precursors produced flower-like $\mathrm{ZnO}$ nanostructures which composed of interconnected porous $\mathrm{ZnO}$ nanosheets with high porosity, as shown in Figure 1E. The as-prepared flower-like $\mathrm{ZnO}$ nanostructures are highly promising candidate for applications of gas sensors. Han et al. (2016) reported the $\mathrm{ZnO}$ hollow spheres with high crystallinity via a simple template process, as shown in Figure 1F. The surfaces of these core-shell spheres are rough, suggesting that polystyrene sphere (PSS) core was coated by $\mathrm{ZnO}$ nanoparticles. The sensor based on $\mathrm{ZnO}$ hollow spheres exhibits good sensing performances.

In this part, the authors make a brief introduction with respect to the hierarchical structures. Hierarchical hollow or porous $\mathrm{ZnO}$ structures exhibit excellent properties for gas sensor applications (Guo et al., 2011, 2012, 2013). These unique hollow structures with large specific surface area and highly porous structures can provide excellent channel and "surface accessibility" for the gas transportation, which is very favorable for facilitating the interaction of $\mathrm{ZnO}$ surface with the gas molecules ( $\mathrm{Gu}$ et al., 2011). No matter how complicated the hierarchical structure, it's all derived from low dimensional nanostructures as building blocks. Hence, the investigation about regulating the structure and morphology is a meaningful and challenge work.

A summary about factors affecting gas sensing performances of $\mathrm{ZnO}$-based gas sensors and improvement approaches is shown in Table 1. The details are described in sections Factors affecting the sensitivity of $\mathrm{ZnO}$ hierarchical structure based Gas sensor, Factors affecting the selectivity of $\mathrm{ZnO}$ hierarchical structure based Gas sensor, and Factors affecting the long-term stability of $\mathrm{ZnO}$ hierarchical structure based Gas sensor as follows. 


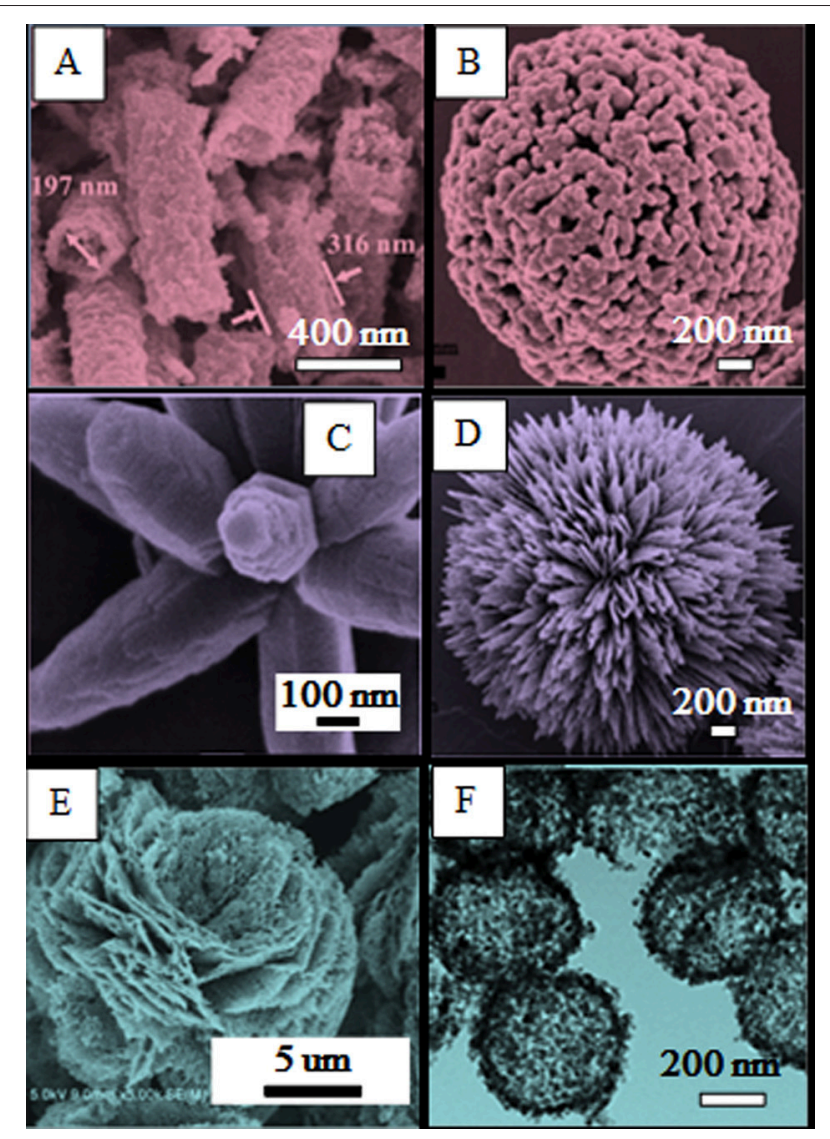

FIGURE 1 | ZnO with different 3D hierarchical structures: (A) Nanofibers assembly by OD structures. Reprinted with permission from Li X. et al. (2015). Copyright (2015) Elsevier Science BV. (B) Nanospheres assembly by OD structures. Reprinted with permission from Chen H. et al. (2016). Copyright (2016) Elsevier Science SA. (C) Flower-like microstructure assembly by 1D structures. Reprinted with permission from Lin et al. (2015). Copyright (2015) Elsevier Science SA. (D) Sea-urchin-like ZnO nanostructures assembly by 1D structures. Reprinted with permission from Chen H. et al. (2016). Copyright (2016) Elsevier Science SA. (E) Porous flower-like ZnO nanostructures assembly by 2D structures. Reprinted with permission from Gu et al. (2011). Copyright (2011) Elsevier Science SA. (F) Core-shell hollow spheres assembly by 2D structures. Reprinted with permission from Han et al. (2016). Copyright (2016) Elsevier Science SA.

\section{Factors Affecting the Sensitivity of $\mathrm{ZnO}$ Hierarchical Structure Based Gas Sensor}

Recently, numerous reports confirmed that ZnO-based nanomaterials are promising candidates for the fabrication of gas sensors (Gu et al., 2013; Wang et al., 2014). Given this, a number of strategies have been proposed for enhancing the gas sensitivity. It can be introduced from the following four aspects.

- Modulation of the dimensional and the exposed crystal facet of their constituting building blocks.

Zhang et al. (2009) synthesized brush-like hierarchical $\mathrm{ZnO}$ nanostructures. The FESEM image (Supplementary Figure 1A) shows that this structure is composed of 6-fold nanorod arrays
TABLE 1 | A summary about factors affecting gas sensing performances of $\mathrm{ZnO}$ hierarchical structure based gas sensors and improvement approaches.

\begin{tabular}{|c|c|c|}
\hline $\begin{array}{l}\text { Main characteristic } \\
\text { indexes which reflect } \\
\text { the performances }\end{array}$ & $\begin{array}{l}\text { Influencing factors and } \\
\text { improvement approaches }\end{array}$ & References \\
\hline \multirow[t]{4}{*}{ Sensitivity } & $\begin{array}{l}\text { Modulation of the } \\
\text { dimensional and the } \\
\text { exposed crystal facet of } \\
\text { their constituting building } \\
\text { blocks }\end{array}$ & Zhang et al., 2009 \\
\hline & $\begin{array}{l}\text { Enhance the porosity of } \\
\text { hierarchical structures }\end{array}$ & $\begin{array}{l}\text { Lei et al., 2017; Song } \\
\text { et al., } 2018\end{array}$ \\
\hline & $\begin{array}{l}\text { Modification by doping with } \\
\text { noble metals and loading } \\
\text { other n-type or p-type MOS } \\
\text { materials }\end{array}$ & Lin et al., 2015 \\
\hline & Control of grain size & Mirzaei et al., 2018 \\
\hline \multirow[t]{2}{*}{ Selectivity } & $\begin{array}{l}\text { Dope with noble metals and } \\
\text { p-type metal oxides }\end{array}$ & Li T. M. et al., 2015 \\
\hline & $\begin{array}{l}\text { Lower the operating } \\
\text { temperature by activating } \\
\text { the sensing material under } \\
\text { UV illumination }\end{array}$ & $\begin{array}{l}\text { Chen Y. et al., 2016; } \\
\text { Espid and Taghipour, } \\
2017\end{array}$ \\
\hline \multirow[t]{3}{*}{ Long-term stability } & $\begin{array}{l}\text { Calcination/annealing as the } \\
\text { post-processing treatment }\end{array}$ & Gu et al., 2011 \\
\hline & $\begin{array}{l}\text { Reduce the working } \\
\text { temperature of gas sensing } \\
\text { element }\end{array}$ & Chen Y. et al., 2016 \\
\hline & $\begin{array}{l}\text { Dope noble metal or } \\
\text { synthesis of mixed oxides }\end{array}$ & Dey, 2018 \\
\hline
\end{tabular}

grown on the side surface of core nanowires. The central stems provide its six prismatic facets as growth platforms for branching of multipod units. The sensor based on these structures shows high sensitivity and fast response.

- Enhance the porosity of hierarchical structures.

Lei et al. (2017) successfully synthesized hierarchical porous $\mathrm{ZnO}$ microspheres assembled from $2 \mathrm{D}$ nanosheets. The high specific surface area and hierarchical pore structure are beneficial to increase the adsorption capacity (Supplementary Figure 1B). Song et al. (2018) reported hierarchical porous $\mathrm{ZnO}$ microflowers which composed of ultrathin nanosheets. From the SEM image (Supplementary Figure 1C), we can see that the surface of nanosheet has lots of pores. The porous structure is favorable for gas sensor to promote the inward/outward gas diffusion and improve gas sensitivity.

- Modification by doping with noble metals and loading other n-type or p-type MOS materials.

It's known that noble metals, such as Pt (Rout et al., 2006), Pd (Yang et al., 2010) and Au (Vallejos et al., 2011) are frequently used in gas sensing materials due to doping can sensitize the $\mathrm{ZnO}$ electronic and structural properties. Lin et al. (2015) reported that $\mathrm{Au}$ nanoparticles were decorated on the surface of hierarchical flower-like $\mathrm{ZnO}$ microstructures, as shown in Supplementary Figure 1D. After Au nanoparticle-decoration, 
the specific surface area is much higher than that of the bare $\mathrm{ZnO}$ (Figure 1C). Au nanoparticles can act as catalysts to accelerate the chemisorption process and greatly improve the sensitivity. So far, heterostructure composites consisting of two metal oxides, such as ( $\mathrm{n}-\mathrm{n}$ type) $\mathrm{SnO}_{2} / \mathrm{ZnO}$ (Park et al., 2013) and (n-p type) $\mathrm{NiO} / \mathrm{ZnO}, \mathrm{AgO} / \mathrm{ZnO}$ (Gandomania et al., 2014) have been successfully prepared and have improved the sensitivity. Liu et al. (2017) reported the $\mathrm{NiO}$ nanoparticles which were decorated onto the surfaces of well-dispersed $\mathrm{ZnO}$ hollow spheres (Supplementary Figures 1E,F). Such hollow structures with rough surfaces endow the $\mathrm{NiO} / \mathrm{ZnO}$ composites high surface areas and abundant active sites, which could facilitate the gas diffusion toward the entire materials and an improvement of the sensitivity (Lee, 2009).

- Control of grain size.

Previous research found that sensors which consist of fine particles of MOS tend to exhibit high sensitivity. Thus, one of the most important factors affecting the sensitivity is grain size (D) of the sensor materials in conjunction with the thickness of the space charge layer (L). Supplementary Figure 1G illustrates three kinds of schematic models for grain-size effects (Shimizu and Egashira, 1999). When D >> 2L, the conductance is limited by Schottky barrier at grain boundaries (grain boundary control). If $\mathrm{D} \geq 2 \mathrm{~L}$, the conductance is limited by necks between grains (neck control). When $\mathrm{D}<2 \mathrm{~L}$, the conductance is controlled by grains themselves (grain control). Among three models, grain control is the most sensitive condition (Mirzaei et al., 2018). The smaller the grain size, the higher the sensitivity of gas sensor. But, excessive decrease in grain size can reduce structural stability.

\section{Factors Affecting the Selectivity of ZnO Hierarchical Structure Based Gas Sensor}

Selectivity is the ability of gas sensor to recognize the target gas in a mixture of other gases. Generally, there are two approaches for enhancing the selectivity of gas sensor. The first one is to synthesize a material which is selective to the specific compound and has very low cross-sensitivity for other compounds. Moreover, the synergistic effect of two component system is greater than the production effect of the two elements. In fact, noble metals and p-type metal oxides have been extensively applied as good catalysts in the two component systems to promote selectivity of sensors (Li T. M. et al., 2015). Another approach to improve the selectivity is to combine with other methods. Recently, some reports have suggested that lowering the operating temperature can be realized by activating the sensing material under UV illumination (Helwig et al., 2009; Lu et al., 2012; Cui et al., 2015). The possible UVactivated selective photo catalysis plays an important role in the enhancement of the selectivity at low temperature (Li X. et al., 2015). It can be explained based on the selective photocatalytic oxidation. The adsorbed oxygen would be re-activated by the photon generated electron-hole pairs, which is conductive to enhancing their reactivity with target gas. After the target gas reacted with the adsorbed oxygen on $\mathrm{ZnO}$ surface, the donated electrons would thus decrease resistance of the sensor and finally reduce the operating temperature (Ho et al., 2015). Chen et al. reported that the mesoporous hollow $\mathrm{ZnO}$ microspheres were applied to detect volatile organic vapors (VOCs) with the help of UV LED illumination at lower temperatures (Chen Y. et al., 2016). The sensor with UV activation at $80^{\circ} \mathrm{C}$ shows a much higher response to ethanol (Supplementary Figure 2A). When the sensor was operated at $220^{\circ} \mathrm{C}$, the UV illumination became ineffective. It shows almost same response to ethanol and acetone (Supplementary Figure 2B). This is because the difference about catalytic conversion of $\mathrm{O}^{2-}$ would have negligible toward them at $220^{\circ} \mathrm{C}$. However, the $\mathrm{O}^{-}$possibly indicated higher preference to ethanol at $80^{\circ} \mathrm{C}$, resulting in the better selectivity. When metal doped-ZnO was illuminated by UV light, the sensor had an appreciable selectivity at low temperature, which was attributed to the heterostructure was in favor of chemical interactions, adsorption of gases and changes in electronic bind energies in the composite (Chen et al., 2008). Espid investigated the photoresponsive behavior of $\mathrm{ZnO} / \mathrm{In}_{2} \mathrm{O}_{3}$ composite sensors (Espid and Taghipour, 2017). When the semiconductor composites are irradiated with photons emitted from a UV source, the photogenerated electron/hole pairs will enhance the conductance of the sensing layer and improve the selectivity.

\section{Factors Affecting the Long-Term Stability of $\mathrm{ZnO}$ Hierarchical Structure Based Gas Sensor}

Stability is a key parameter for the long-term development of gas sensors, which determines its application state in the real market. Generally, the long-term stability refers to the attenuation degree of gas sensing performances (e.g., sensitivity, selectivity, response and recovery time) during a certain period of time. When the sensor is in working state, working conditions including high temperature and toxic gases can reduce the stability. When the sensor is in normal storage state, changes of humidity, fluctuations of temperature in the surrounding atmosphere may also interfere with the stability of sensor. At present, there is not a recognized method to improve stability of $\mathrm{ZnO}$-based gas sensors. Stability can be increased to some extent by calcination/ annealing as the post-processing treatment (Gu et al., 2011) and reducing the working temperature of gas sensing element. Chen et al. tested the long-term stability of $\mathrm{ZnO}$-based sensor working at $80^{\circ} \mathrm{C}$ with UV activitation (Chen Y. et al., 2016). The sensor test lasted 1 month (Supplementary Figure 2C). In the first 2 days, the response values dropped significantly, which might be related to the "pre-aging" effect. In the next few days, the sensor response became stabilized and showed a good long-term stability. It might be because the microstructure of the materials had little change under low temperature with low-powered UV activation. In addition, doping noble metal or synthesis of mixed oxides can also increase the stability of the sensors (Dey, 2018).

\section{GAS SENSING MECHANISM OF ZnO HIERARCHICAL STRUCTURE BASED GAS SENSOR}

By summarizing the methods to improve the gas sensing performances in section Gas Sensing Performances of $\mathrm{ZnO}$ Based Gas Sensor, we find that metal doping is an excellent 
method to promote sufficient reaction between sensing material and target gas.

The gas sensing mechanism of noble metals doped- $\mathrm{ZnO}$ hierarchical structures based gas sensors is explained as an example. This process mainly involves two effects: chemical effect and electronic effect (Zhu and Zeng, 2017). Firstly, the chemical effect is related to spillover process (Nakate et al., 2016). Oxygen molecules were adsorbed on the surface and grain boundary of $\mathrm{ZnO}$, forming the oxygen ions. The sensitization of noble metals increases the quantity of oxygen species and accelerates the surface reaction, causing an expansion of charge depletion layer, which results in a higher baseline resistance (Supplementary Figures 3A,B). When the reducing gas is introduced, the catalysis of noble metals may give rise to the dissociation of target gas molecules. The trapped electrons are released and transmitted to the conduction band, resulting in a remarkable decrease in depletion layer with a lower resistance. Secondly, the electric effect is produced by contact resistance of noble metal modified $\mathrm{ZnO}$ gas sensors (Hosseini et al., 2015). Electrons from the conduction band of $\mathrm{ZnO}$ transfer into noble metals owing to their work functions are different, forming the Schottky barriers at noble metal-ZnO interface, which leading to generate the additional depletion region near $\mathrm{ZnO}$ surface (Supplementary Figure 3C).

Therefore, the enhanced sensing performance was ascribed to the spillover phenomenon, the formation of Schottky barriers at the interface between noble metals and $\mathrm{ZnO}$, more introduced surface active sites and effective surface areas (Hosseini et al., 2015).

\section{CONCLUSION}

A study on gas sensing performances of $\mathrm{ZnO}$ hierarchical structures has been shortly summarized in this review. Firstly, unique 3D hierarchical architectures with high sensing capabilities are discussed by modifying surface morphologies. Small grain size, high effective specific surface area and porosity are favorable to the enhancement of gas sensing performances. Therefore, the preparation of the desired 3D hierarchical structure can lay a solid foundation for the development of gas sensor. Then, factors that affect the sensitivity, selectivity and stability of $\mathrm{ZnO}$ hierarchical structures based gas sensors and their improvement strategies are summarized separately. Among these methods, additive doping and UV-light irradiation are

\section{REFERENCES}

Benounis, T. M., Ngnui, T. A., Jaffrezic, N., and Dutasta, J. P. (2008). NIR and optical fiber sensor for gases detection produced by transformation oil degradation. Sens. Actuators A Phys. 141, 76-83. doi: 10.1016/j.sna.2007. 07.036

Bodzenta, J., Burak, B., Gacek, Z., Jakubik, W. P., Kochowski, S., and Urbanczyk, M. (2002). Thin palladium film as a sensor of hydrogen gas dissolved in transformer oil. Sens. Actuators B Chem. 87, 82-87. doi: 10.1016/S0925-4005(02)00221-6

Chen, H., Ma, S. Y., Jiao, H. Y., Yang, G. J., Xu, X. L., Wang, T. T., et al. (2016). The effect microstructure on the gas properties of Ag doped zinc oxide sensors: more effective methods to improve gas sensing performances. The former can increase charge carrier concentration and decrease activation energy. The latter can promote the catalytic oxidation reaction between target gases and oxygen ions, thus reduce the working temperature and power consumption. Numerous reports indicate that the integration of metal doped-oxide and UV excitation is one of the most effective and workable attempts to achieve high sensor performances. The composite oxides based sensors under UV illumination have better charge separation, which benefit for the gas performances enhancement of the sensors. We hope our work is helpful for further exploration on higher gas sensing performances of MOS sensing materials for detecting dissolved fault gases in transformer oil. Finally, gas sensing mechanism of noble metal sensitized $\mathrm{ZnO}$ is illuminated from the point of view of chemical effect and electronic effect. Nevertheless, the authors suggest only a few possible ways to improve the existed oxygen-absorbed model in recent researchers. Much effort should be made to hunt for an integration of different models which was used to explain the gas sensing reaction.

\section{AUTHOR CONTRIBUTIONS}

$\mathrm{HZ}$ and $\mathrm{W}-\mathrm{GC}$ conceived and designed the experiments, $\mathrm{HZ}$ and Y-QL performed the experiments, HZ and Z-HS analyzed the data, HZ wrote the manuscript with input from all authors. All authors read and approved the manuscript.

\section{ACKNOWLEDGMENTS}

This work was supported by the Science Fund for Creative Research Groups of the National Natural Science Foundation of China (Grant No. 51321063), the Joint Fund of the National Natural Science Foundation of China and the Smart Grid of State Grid Corporation of China (Grant No. U1766217), and the Scientific Research Fund of Chongqing University of Arts and Sciences (2017RDQ38).

\section{SUPPLEMENTARY MATERIAL}

The Supplementary Material for this article can be found online at: https://www.frontiersin.org/articles/10.3389/fchem. 2018.00508/full\#supplementary-material spheres and sea-urchin-like nanostructures. J. Alloy Compd. 687, 342-351. doi: 10.1016/j.jallcom.2016.06.153

Chen, L. Y., Bai, S. L., Zhou, G. J., Li, D. Q., Chen, A. F., and Chung, C. L. (2008). Synthesis of $\mathrm{ZnO}-\mathrm{SnO}_{2}$ nanocomposites by microemulsion and sensing properties for $\mathrm{NO}_{2}$. Sens. Actuators B Chem. 134, 360-366. doi: 10.1016/j.snb.2008.04.040

Chen, Y., Li, X. G., Li, X. X., Wang, J., and Tang, Z. N. (2016). UV activated hollow $\mathrm{ZnO}$ microspheres for selective ethanol sensors at low temperatures. Sens. Actuators B Chem. 232, 158-164. doi: 10.1016/j.snb.2016.03.138

Cho, S., Kim, S., Jung, D. W., and Lee, K. H. (2011). Formation of quasi-single crystalline porous $\mathrm{ZnO}$ nanostructures with a single large cavity. Nanoscale 3, 3841-3848. doi: 10.1039/c1nr10609k 
Christina, A. J., Salam, M. A., Rahman, Q. M., Wen, F. S., Ang, S. P., and Voon, W. (2018). Causes of transformer failures and diagnostic methods: a review. Renew. Sust. Energ. Rev. 82, 1442-1456. doi: 10.1016/j.rser.2017.05.165

Cui, J. B., Shi, L. Q., Xie, T. F., Wang, D. J., and Lin, Y. H. (2015). UVlight illumination room temperature $\mathrm{HCHO}$ gas-sensing mechanism of $\mathrm{ZnO}$ with different nanostructures. Sens. Actuators B Chem. 227, 220-226. doi: $10.1016 /$ j.snb.2015.12.010

Das, M., and Sarkar, D. (2017). One-pot synthesis of zinc oxide-polyaniline nanocomposite for fabrication of efficient room temperature ammonia gas sensor. Ceram. Int. 43, 11123-11131. doi: 10.1016/j.ceramint.2017.05.159

Dey, A. (2018). Semiconductor metal oxide gas sensors: a review. Mater. Sci. Eng. B 229, 206-217. doi: 10.1016/j.mseb.2017.12.036

Ding, J., Li, X., Cao, J., Sheng, L., Yin, L., and Xu, X. (2014). New sensor for gases dissolved in transformer oil based on solid oxide fuel cell. Sens. Actuators $B$ Chem. 202, 232-239. doi: 10.1016/j.snb.2014.05.061

Espid, E., and Taghipour, F. (2017). Development of highly sensitive $\mathrm{ZnO} / \mathrm{In}_{2} \mathrm{O}_{3}$ composite gas sensor activated by UV-LED. Sens. Actuators B Chem. 241, 828-839. doi: 10.1016/j.snb.2016.10.129

Fan, J. M., Wang, F., Sun, Q. Q., Ye, H. S., and Jiang, Q. J. (2018). Application of polycrystalline $\mathrm{SnO}_{2}$ sensor chromatographic system to detect dissolved gases in transformer oil. Sens. Actuators B Chem. 267, 636-646. doi: 10.1016/j.snb.2018.04.014

Gandomania, S. K., Yousefib, R., Sheinic, F. J., and Huang, N. M. (2014). Optical and electrical properties of p-type Ag-doped $\mathrm{ZnO}$ nanostructures. Ceram. Int. 40, 7957-7963. doi: 10.1016/j.ceramint.2013.12.145

Ganesh, R. S., Durgadevi, E., Navaneethan, M., Patil, V. L., Ponnusamy, S., Muthamizhchelvan, C., et al. (2017). Low temperature ammonia gas sensor based on $\mathrm{Mn}$-doped $\mathrm{ZnO}$ nanoparticle decorated microspheres. J. Alloys Compd. 721, 182-190. doi: 10.1016/j.jallcom.2017.05.315

Gardon, M., and Guilemany, J. M. (2013). A review on fabrication, sensing mechanisms and performance of metal oxide gas sensors. J. Mater. Sci. Mater. Electron. 24, 1410-1421. doi: 10.1007/s10854-012-0974-4

Gu, C. P., Huang, J. R., Wu, Y. J., Zhai, M. H., Sun, Y. F., Liu, J. H., et al. (2011). Preparation of porous flower-like $\mathrm{ZnO}$ nanostructures and their gas-sensing property. J. Alloy Compd. 509, 4499-4504. doi: 10.1016/j.jallcom.2010.11.078

Gu, C. P., Li, S. S., Huang, J. R., Shi, C. C., and Liu, J. H. (2013). Preferential growth of long $\mathrm{ZnO}$ nanowires and its application in gas sensor. Sens. Actuators B Chem. 177, 453-459. doi: 10.1016/j.snb.2012.11.044

Guo, W. W. (2016). ZnO nanosheets assembled different hierarchical structures and their gas sensing properties. J Mater Sci. Mater. Electron. 27, 7302-7310. doi: 10.1007/s10854-016-4699-7

Guo, W. W., Liu, T. M., Sun, R., Chen, Y., Zeng, W., and Wang, Z. C. (2013). Hollow, porous, and yttrium functionalized $\mathrm{ZnO}$ nanospheres with enhanced gas-sensing performances. Sens. Actuators B Chem. 178, 53-62. doi: 10.1016/j.snb.2012.12.073

Guo, W. W., Liu, T. M., Zeng, W., Liu, D. J., Chen, Y., and Wang, Z. C. (2011). Gassensing property improvement of $\mathrm{ZnO}$ by hierarchical flower-like architectures. Mater. Lett. 65, 3384-3387. doi: 10.1016/j.matlet.2011.07.059

Guo, W. W., Liu, T. M., Zhang, H. J., Sun, R., Chen, Y., Zeng, W., et al. (2012). Gas-sensing performance enhancement in $\mathrm{ZnO}$ nanostructures by hierarchical morphology. Sens. Actuators B Chem. 166, 492-499. doi: 10.1016/j.snb.2012.02.093

Han, B. Q., Liu, X., Xing, X. X., Chen, N., Xiao, X. C., Liu, S. Y., et al. (2016). A high response butanol gas sensor based on $\mathrm{ZnO}$ hollow spheres. Sens. Actuators B Chem. 237, 423-430. doi: 10.1016/j.snb.2016.06.117

Helwig, A., Müller, G., Sberveglieri, G., and Eickhoff, M. (2009). On the lowtemperature response of semiconductor gas sensors. J. Sens. 2009, 1-17. doi: $10.1155 / 2009 / 620720$

Ho, Y. H., Huang, W. S., Chang, H. C., Wei, P. K., Sheen, H. J., and Tian, W. C. (2015). Ultraviolet-enhanced room-temperature gas sensing by using floccule-like zinc oxide nanostructures. Appl. Phys. Lett. 106, 1831031-1831034. doi: 10.1063/1.4919921

Hosseini, Z. S., Mortezaali, A., Iraji, A., and Fardindoost, S. (2015). Sensitive and selective room temperature $\mathrm{H}_{2} \mathrm{~S}$ gas sensor based on $\mathrm{Au}$ sensitized vertical $\mathrm{ZnO}$ nanorods with flower-like structures. J. Alloys Compd. 628, 222-229. doi: 10.1016/j.jallcom.2014.12.163

Lee, J. H. (2009). Gas sensors using hierarchical and hollow oxide nanostructures: overview. Sens. Actuators B Chem. 140, 319-336. doi: 10.1016/j.snb.2009.04.026
Lei, C. S., Pi, M., Jiang, C. J., Cheng, B., and Yu, J. G. (2017). Synthesis of hierarchical porous zinc oxide $(\mathrm{ZnO})$ microspheres with highly efficient adsorption of Congo red. J. Colloid Interrface Sci. 490, 242-251. doi: 10.1016/j.jcis.2016.11.049

Li, T. M., Zeng, W., and Wang, Z. C. (2015). Quasi-one-dimensional metal-oxidebased heterostructural gas-sensing materials: a review. Sens. Actuators B Chem. 221, 1570-1585. doi: 10.1016/j.snb.2015.08.003

Li, W. Q., Ma, S. Y., Yang, G. J., Mao, Y. Z., Luo, J., Cheng, L., et al. (2015). Preparation, characterization and gas sensing properties of pure and Ce doped $\mathrm{ZnO}$ hollow nanofibers. Mater. Lett. 138, 188-191. doi: 10.1016/j.matlet.2014.09.130

Li, X., Li, X., Wang, J., and Lin, S. (2015). Highly sensitive and selective roomtemperature formaldehyde sensors using hollow $\mathrm{TiO}_{2}$ microspheres, Sens. Actuators B Chem. 219, 158-163. doi: 10.1016/j.snb.2015.05.031

Liao, L., Mai, H. X., Yuan, Q., Lu, H. B., Li, J. C., Liu, C., et al. (2008). Single $\mathrm{CeO}_{2}$ nanowire gas sensor supported with $\mathrm{Pt}$ nanocrystals: gas sensitivity, surface bond states, and chemical mechanism. J. Phys. Chem. C 112, 9061-9065. doi: $10.1021 /$ jp7117778

Lin, Y., Wei, W., Wang, Y., Zhou, J. R., Sun, D. M., Zhang, X. D., et al. (2015). Highly stabilized and rapid sensing acetone sensor based on $\mathrm{Au}$ nanoparticle-decorated flower-like $\mathrm{ZnO}$ microstructures. J. Alloy Compd. 650, 37-44. doi: 10.1016/j.jallcom.2015.07.242

Liu, C., Zhao, L. P., Wang, B. Q., Sun, P., Wang, Q. J., Gao, Y., et al. (2017). Acetone gas sensor based on $\mathrm{NiO} / \mathrm{ZnO}$ hollow spheres: Fast response and recovery, and low (ppb) detection limit. J. Colloid Interrface Sci. 495, 207-215. doi: 10.1016/j.jcis.2017.01.106

Lu, G. Y., Xu, J., Sun, J. B., Yu, Y. S., Zhang, Y. Q., and Liu, F. M. (2012). UV-enhanced room temperature $\mathrm{NO}_{2}$ sensor using $\mathrm{ZnO}$ nanorods modified with $\mathrm{SnO}_{2}$ nanoparticles. Sens. Actuators B Chem. 162, 82-88. doi: 10.1016/j.snb.2011.12.039

Ma, G. M., Li, C. R., Luo, Y. T., Mu, R. D., and Wang, L. (2012). High sensitive and reliable fiber bragg grating hydrogen sensor for fault detection of power transformer. Sens. Actuators B Chem. 169, 195-198. doi: 10.1016/j.snb.2012.04.066

Mariprasath, T., and Kirubakaran, V. (2018). A real time study on condition monitoring of distribution transformer using thermal imager. Infrared Phys. Technol. 90, 78-86. doi: 10.1016/j.infrared.2018.02.009

Mirzaei, A., Kim, J. H., Kim, H. W., and Kim, S. S. (2018). How shell thickness can affect the gas sensing properties of nanostructured materials: Survey of literature. Sens. Actuators B Chem. 258, 270-294. doi: 10.1016/j.snb.2017.11.066

Mo, M. S., Lim, S. H., Mai, Y. W., Zheng, R. K., and Ringer, S. P. (2008). In situ selfassembly of thin $\mathrm{ZnO}$ nanoplatelets into hierarchical mesocrystal microtubules with surface grafting of nanorods: a general strategy towards hollow mesocrystal structures. Adv. Mater. 20, 339-342. doi: 10.1002/adma.2007 01137

Nakate, U. T., Patil, P., Bulakhe, R. N., Lokhande, C. D., Kale, S. N., Naushad, M., et al. (2016). Sprayed zinc oxide films: ultra-violet light-induced reversible surface wettability and platinum-sensitization-assisted improved liquefied petroleum gas response. J. Colloid Interface Sci. 480, 109-117. doi: 10.1016/j.jcis.2016.07.010

Park, S., An, S., Mun, Y., and Lee, C. (2013). UV-enhanced $\mathrm{NO}_{2}$ gas sensing properties of $\mathrm{SnO}_{2}$-core/ZnO-shell nanowire at room temperature. ACS Appl. Mater. Interf. 5, 4285-4292. doi: 10.1021/am400500a

Rout, C. S., Govindaraj, A., and Rao, C. (2006). High-sensitivity hydrocarbon sensors based on tungsten oxide nanowires. J. Mater. Chem. 16, 3936-3941. doi: 10.1039/B607012B

Seiyama, T., Kato, A., Fujiishi, K., and Nagatani, M. (1962). A new detector for gaseous components using semiconductive thin films. Anal. Chem. 34, 1502-1503. doi: 10.1021/ac60191a001

Shimizu, Y., and Egashira, M. (1999). Basic aspects and challenges of semiconductor gas sensors. MRS Bull. 24, 18-24. doi: $10.1557 /$ S0883769400052465

Siada, A. A., and Hmood, S. (2015). A new fuzzy logic approach to identify power transformer criticality using dissolved gas-in-oil analysis. Int. J. Electr. Power 67, 401-408. doi: 10.1016/j.ijepes.2014.12.017

Song, L. M., Yue, H., Li, H. Y., Liu, L., Li, Y., Du, L. T., et al. (2018). Hierarchical porous $\mathrm{ZnO}$ microflowers with ultra-high ethanol gas sensing at low concentration. Chem. Phys. Lett. 699, 1-7. doi: 10.1016/j.cplett.2018.03.021 
Sun, R., Wang, Z. C., Saito, M., Shibata, N., and Ikuhara, Y. (2015). Atomistic mechanisms of nonstoichiometry-induced twin boundary structural transformation in titanium dioxide. Nat. Commun., 6, 7120-7126. doi: $10.1038 /$ ncomms 8120

Sun, Y. F., Liu, S. B., Meng, F. L., Liu, J. Y., Jin, Z., Kong, L. T., et al. (2012). Metal oxide nanostructures and their gas sensing properties: a review. Sensors 12, 2610-2631. doi: 10.3390/s120302610

Uddin, A., Yaqoob, U., and Chung, G. S. (2016). Dissolved hydrogen gas analysis in transformer oil using $\mathrm{Pd}$ catalyst decorated on $\mathrm{ZnO}$ nanorod array. Sens. Actuators B Chem. 226, 90-95. doi: 10.1016/j.snb.2015.11.110

Vallejos, S., Stoycheva, T., Umek, P., Navio, C., Snyders, R., Bittencourt, C., et al. (2011). Au nanoparticle-functionalised $\mathrm{WO}_{3}$ nanoneedles and their application in high sensitivity gas sensor devices. Chem. Commun. 47, 565-567. doi: $10.1039 /$ c0cc02398a

Wang, H., Qu, Y., Chen, H., Lin, Z. D., and Dai, K. (2014). Highly selective n-butanol gas sensor based on mesoporous $\mathrm{SnO}_{2}$ prepared with hydrothermal treatment. Sens. Actuators B Chem. 201, 153-159. doi: 10.1016/j.snb.2014.04.049

Wang, X., Liu, W., Liu, J., Wang, F., Kong, J., Qiu, S., et al. (2012). Synthesis of nestlike $\mathrm{ZnO}$ hierarchically porous structures and analysis of their gas sensing properties. ACS Appl. Mater. Interfaces 4, 817-825. doi: 10.1021/am201476b

Xu, T. T., Xu, Y. M., Zhang, X. F., Deng, Z. P., Huo, L. H., and Gao, S. (2018). Enhanced $\mathrm{H}_{2} \mathrm{~S}$ Gas-Sensing Performance of $\mathrm{Zn}_{2} \mathrm{SnO}_{4}$ Lamellar Micro-Spheres. Front. Chem. 6:165. doi: 10.3389/fchem.2018.00165

Yang, D. J., Kamienchick, I., Youn, D. Y., Rothschild, A., and Kim, I. D. (2010). Ultrasensitive and highly selective gas sensors based on electrospun $\mathrm{SnO}_{2}$ nanofibers modified by Pd loading. Adv. Funct. Mater. 20, 4258-4264. doi: 10.1002/adfm.201001251
Yang, F., Jung, D., and Penner, R. M. (2011). Trace detection of dissolved hydrogen gas in oil using a palladium nanowire array. Anal. Chem. 83, 9472-9477. doi: $10.1021 /$ ac2021745

Zeng, W., Zhu, L. P., Zhang, Z. Y., and Ye, Z. Z. (2015). Fabrication of gas sensor based on mesoporous rhombus-shaped $\mathrm{ZnO}$ rod arrays. Sens. Actuators B Chem. 208, 112-121. doi: 10.1016/j.snb.2014.11.024

Zhang, Y., Xu, J. Q., Xiang, Q., Li, H., Pan, Q. Y., and Xu, P. C. (2009). Brush-Like hierarchical ZnO nanostructures: synthesis, photoluminescence and gas sensor properties. J. Phys. Chem. C 113, 3430-3435. doi: 10.1021/jp80 92258

Zhao, T., Nguyen, N. T., Xie, Y., Sun, X. F., Li, Q., and Li, X. (2017). Inorganic Nanocrystals Functionalized Mesoporous Silica Nanoparticles: Fabrication and Enhanced Bio-applications. Front. Chem. 5:118. doi: 10.3389/fchem.2017.00118

Zhu, L., and Zeng, W. (2017). Room-temperature gas sensing of ZnO-based gas sensor: A review. Sens. Actuators A Phys. 267, 242-261. doi: 10.1016/j.sna.2017. 10.021

Conflict of Interest Statement: The authors declare that the research was conducted in the absence of any commercial or financial relationships that could be construed as a potential conflict of interest.

Copyright (c) 2018 Zhang, Chen, Li and Song. This is an open-access article distributed under the terms of the Creative Commons Attribution License (CC BY). The use, distribution or reproduction in other forums is permitted, provided the original author(s) and the copyright owner(s) are credited and that the original publication in this journal is cited, in accordance with accepted academic practice. No use, distribution or reproduction is permitted which does not comply with these terms. 